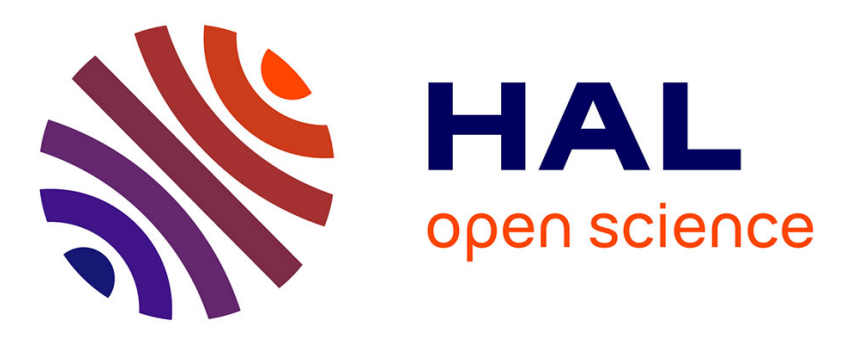

\title{
A review on optimisation of part quality inspection planning in a multi-stage manufacturing system
}

Mohammad Rezaei-Malek, Mehrdad Mohammadi, Jean-Yves Dantan, Ali

Siadat, Reza Tavakkoli-Moghaddam

\section{- To cite this version:}

Mohammad Rezaei-Malek, Mehrdad Mohammadi, Jean-Yves Dantan, Ali Siadat, Reza TavakkoliMoghaddam. A review on optimisation of part quality inspection planning in a multi-stage manufacturing system. International Journal of Production Research, 2018, 57 (15-16), pp.4880-4897. 10.1080/00207543.2018.1464231 . hal-02461149

\section{HAL Id: hal-02461149 \\ https://hal.science/hal-02461149}

Submitted on 30 Jan 2020

HAL is a multi-disciplinary open access archive for the deposit and dissemination of scientific research documents, whether they are published or not. The documents may come from teaching and research institutions in France or abroad, or from public or private research centers.
L'archive ouverte pluridisciplinaire HAL, est destinée au dépôt et à la diffusion de documents scientifiques de niveau recherche, publiés ou non, émanant des établissements d'enseignement et de recherche français ou étrangers, des laboratoires publics ou privés. 


\title{
A review on optimisation of part quality inspection planning in a multi-stage manufacturing system
}

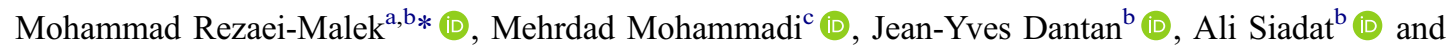 \\ Reza Tavakkoli-Moghaddam, ${ }^{\mathrm{a}, \mathrm{b}, \mathrm{d}}$ (]) \\ ${ }^{a}$ School of Industrial Engineering, College of Engineering, University of Tehran, Tehran, Iran; ${ }^{b}$ Arts et Métiers Paris Tech, LCFC, \\ 57078 Metz, France; ${ }^{c} I M T$ Atlantique, Lab-STICC, UBL, F-29238 Brest, France; ${ }^{d}$ Universal Scientific Education and Research \\ Network (USERN), Tehran, Iran
}

\begin{abstract}
In multi-stage manufacturing systems, optimisation of part quality inspection planning (PQIP) problem means to determine the optimal time, place and extent of inspection activities for assessing the significant quality characteristics of products while maximising the system efficiency. An inspection activity is capable of detecting the produced defects partially and accordingly prevents further processing of them in downstream and more importantly avoids them to reach customers. In this paper, the existing researches on the optimisation of the part quality inspection are surveyed from the viewpoint of the considered production system characteristics; the applied modelling approaches and solution methodologies. This review found that although numerous works have been already done on the PQIP, the development of multiobjective optimisation frameworks considering real production constraints under parameters uncertainty is necessary. Also, by the Industry 4.0 trend, the creation of integrated models aiming to plan the inspection, maintenance and production activities simultaneously, seems to be an important potential future research direction.
\end{abstract}

Keywords: inspection planning; optimisation; operational research; multi-stage manufacturing system; literature review

\section{Introduction}

The paramount significance of Total Quality Management has been quite understood by all the industries over recent decades. Indeed, manufacturing companies need to reach a high level of quality in their services or products to maintain their profitability and global competitiveness (Mohammadi 2015). To this end, they are employing a wide range of tools to boost quality in the manufacturing process. Some of the essential tools are statistical process control (SPC), six sigma $(6 \sigma)$, process improvement and inspection (Montgomery 2009).

Sloppy design of products, inefficient manufacturing methods, tool and machine malfunction and low quality of raw materials are some of the external reasons which cause quality problems in manufacturing systems. Hence, performing an appropriate quality control programme can lead system to reach a high level of quality for products in the presence of these destructive reasons. Indeed, different research directions have been established to achieve a high level of quality for products in manufacturing systems: quality in management, service, manufacturing and design (Mohammadi et al. 2015). In this review paper, concentration is focused on a certain tool for attaining high quality in manufacturing, namely inspection.

Inspection is 'an organised examination or formal evaluation exercise. Inspection involves the examination, measurement, testing, gauging, and comparison of materials or items. An inspection determines if the material or item is in proper quantity and condition and if it conforms to the applicable or specified requirements' (Winchell 1996). Inspection can be done in every production stage and based on the result of the inspection; if a defective item is detected, it can either be reworked, repaired, replaced or scrapped to avoid further processing and delivering to a customer. The research domain of part quality inspection in a multi-stage manufacturing system (MMS), studies the posed costs and obtained benefits by inspection efforts with the purpose of assessing the manufacturing quality (Mohammadi et al. 2015).

In most of the MMSs, raw materials pass a series of different manufacturing stages to be processed and changed to the final products. In these systems, the output of each manufacturing stage, except the last one, is the input for the next 
one. Because of non-ideal manufacturing situations and stochastic nature of the production stages, deviations from design specifications happen that result in low level of products quality (Mohammadi et al. 2017).

Part quality inspection in the MMSs is an important issue because of the multi-stage structure of the systems which causes various alternatives for inspection. In these systems, if an item is recognised as a defect, there are four possible actions: (1) Rework: the defective item will be sent to the previous production stage(s) for modification, (2) Repair: the defective item will be repaired and proceeds to the next stage but in a downgraded quality form, (3) Replace: the defected item will be replaced with a conforming one and (4) Scrap: the defective item will be scrapped. The scrap activities raise the production cost because of wasting material, time and energy. On the other side, passing the undetected defective products through subsequent production stages raises production cost by establishing more rework and repair stages required to restore the defect item (Colledani et al. 2014). There are two distinct strategies, first, performing an inspection activity after each production stage to find defects quickly after corresponding operation of that stage. This would decrease the probability of passing non-conforming items across the MMS. Nevertheless, the cost of inspection after each production stage in the system might be more elevated than the savings earned by the early recognising defects. Second, the inspection could be employed after the final production stage and at no other location. This strategy would reduce the cost of the inspection activities, but there might be a non-conformance in the final product corresponding to the first stage. So, it would be necessary to repeat all production stages that results in an increase in the total manufacturing cost. To minimise the total cost, in terms of production, inspection, scrap, replace, rework and repair, it is practical to establish a balance of different costs and find an optimal inspection plan (Shetwan, Vitanov, and Tjahjono 2011).

In this paper, the existing research works on part quality inspection planning (PQIP) problem will be reviewed. For this aim, the keywords 'inspection planning' in combination with 'multi-stage production/manufacturing system' were used to find relevant journal articles, books, theses and conference contributions in the two most comprehensive databases; Scopus and ProQuest. $67 \%$ of the research works have been published by $11 \%$ of the journals (see Figure 1). Noteworthy, International Journal of Production Research has the highest impact (i.e. 16.7\%) among all. The rest of studies (i.e. 33\%) have been published by the journals with less than two research works. Figure 2 illustrates the number of issued papers during the different periods, and as can be seen, there is an increasing trend for research publishing. Although the last period in Figure 2 includes seven years (2010 to 2017), it is expected that the increasing trend of publishing in this field will be continued for the second decade of the twenty-first century. Actually, the associate literature will be investigated from different viewpoints: production system characteristics, methodology characteristics and optimisation framework. Although Raz (1986), Mandroli, Shrivastava, and Ding (2006) and Shetwan, Vitanov, and Tjahjono (2011) reviewed the literature of the PQIP problem in the different time periods, this paper covers not only their investigated researches, but also the state-of-the-art literature up to 2017. In addition, this paper investigates and classifies the literature based on two new and practical perspectives: Optimisation under uncertainty and integrated optimisation with maintenance and production planning. In this way, the readers of this paper will get familiar comprehensively with the development trend and research gaps of the PQIP problem literature.

The rest of the paper is structured as follows. Section 2 describes the general decision-making procedure of the PQIP problem in a MMS. Section 3 reviews the literature regarding the considered production system characteristics. The applied modelling and solution methodologies in the literature are investigated in Section 4. Section 5 discusses the integrated optimisation approach. The literature is then analysed in Section 6 by providing the gaps and future research works.

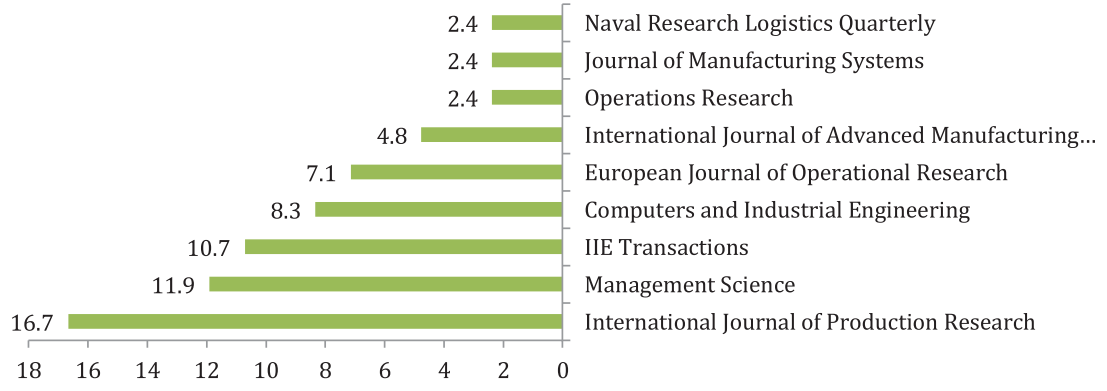

Figure 1. Percentage of the published research works in the most famous journals. 


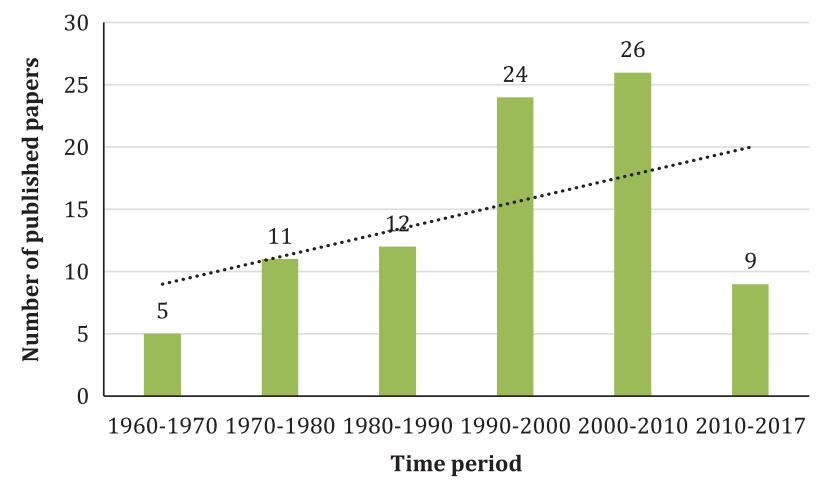

Figure 2. Number of published papers in different periods.

\section{PQIP problem}

Figure 3 schematically shows the PQIP problem in a MMS. This system contains $N$ different production stages that each of them can be followed by an inspection stage $m$. The figure illustrates the decision problems between each two adjacent production stages. As can be seen, a typical PQIP problem consists of seven main questions as follows:

Q1: Is Quality Characteristic (QC) $k$ of product(s) inspected after production stage $i$ in period $t$ ?

Q2: All the items are inspected or a fraction of them (i.e. sampling)?

Q3: What are the parameters of the sampling inspection?

Q4: What is the inspection threshold or specification region?

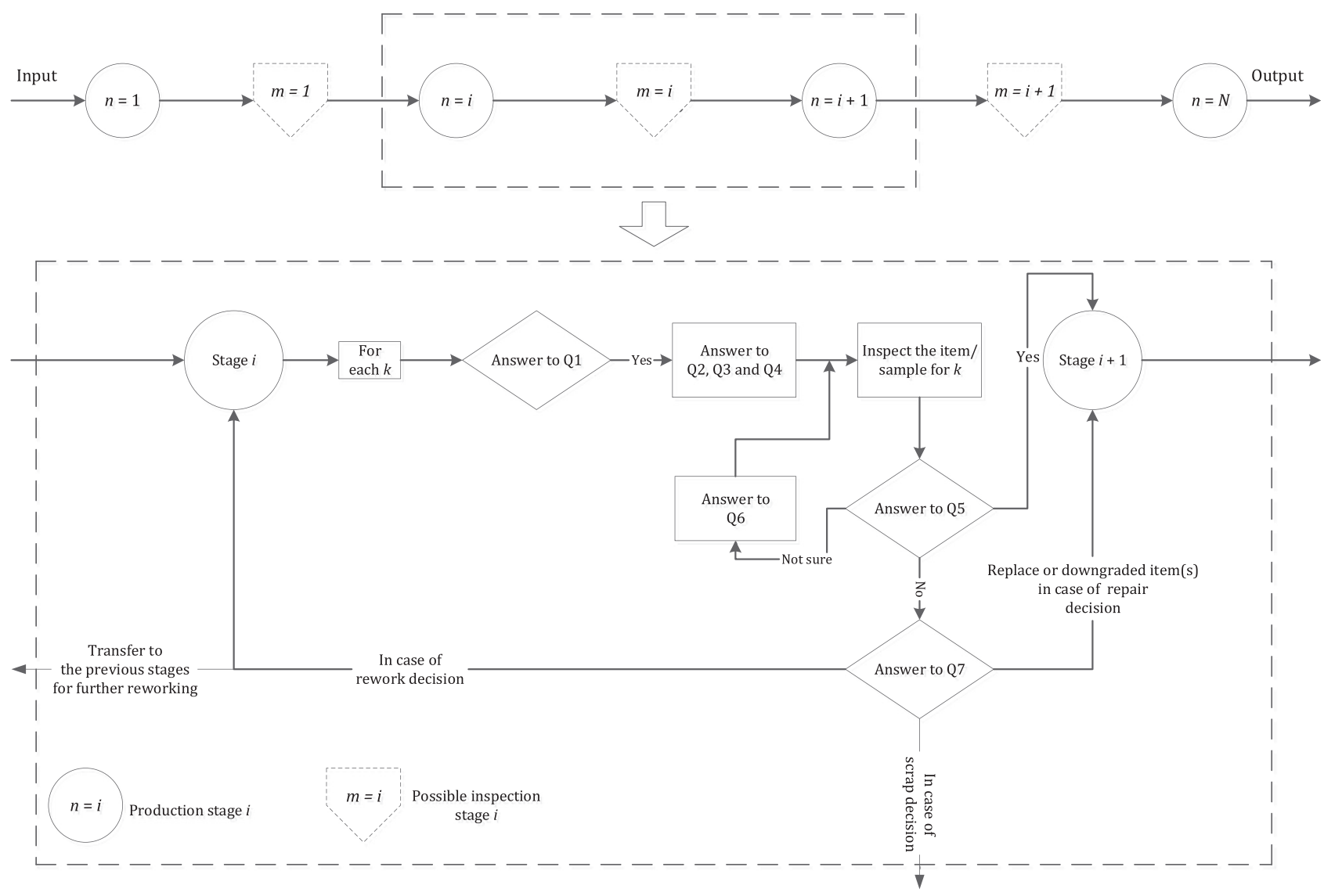

Figure 3. PQIP problem in a MMS in period $t$. 
Q5: After the inspection performance, does the item/sample conform to the inspection threshold/specification region?

Q6: What is the number of inspection repetitions in case of being not sure about the inspection result?

Q7: In case of non-conformity, which waste management strategy would be performed (i.e. rework, repair, replace or scrap) for each non-conforming item?

In fact, the product may pass to the next stage or to a customer without at least one inspected QC, and the product will be undoubtedly sent to the next stage when inspection shows conformity with the design specification.

Using an inspection plan in a MMS poses an additional cost, but in an imperfect MMS, a certain level of inspection will reduce total manufacturing cost and enhance the customer satisfaction as well. In this case, the associated cost of inspection will be covered by the benefits obtained through the detection of defects (Mohammadi 2015).

Noteworthy, performing an inspection after every production stage will reduce the scrap, replacing, reworking, and downgrading costs and avoid reaching non-conforming products to customer(s). On the other hand, unnecessary and often too inspections pose huge costs of equipment, staff, time, space and interrupt the manufacturing process which results in extra work-in-progress (WIP) and flows. Hence, if inspections are done unnecessarily, then higher total costs will incur (Mohammadi 2015).

\section{MMS characteristics}

Regarding the literature of the PQIP problem, the characteristics of investigated MMSs fall into seven main categories (Mohammadi 2015); (1) manufacturing structure, (2) manufacturing/inspection flow, (3) inspection type, (4) inspection strategy, (5) inspection errors, (6) failure type and rate and (7) non-conforming strategy. Each of these main categories is elaborated through some sub-categories as follows. Table 1 illustrates the features of the literature regarding these characteristics.

\subsection{Production structure}

There are three main manufacturing structures according to the product flow alongside a MMS (Mandroli, Shrivastava, and Ding 2006; Mohammadi 2015):

(1) Serial structure: all products pass the same successive manufacturing stages sequentially.

(2) Convergent structure: each item passes a certain set of successive manufacturing stages sequentially while different paths may be converged in a particular stage. On the other side, each production stage has at most one successor but many predecessor stages (e.g. assembly process).

(3) Nonserial structure: each item passes distinct stages sequentially while each production stage may have several successors and predecessor stages.

In contrary to the non-serial and convergent structures, the serial structure is the most-considered in the literature (see Figure 4(a)) because the defects propagation can be easily modelled in a mathematical way. For instance, in the convergent structure, mathematically tracking the root defects after the convergent stage is complex.

\subsection{Production/inspection flow}

A production line in a MMS can produce either a specific product or multiple types of the same product family. In this regard, inspections of this manufacturing line can be done per item or batch/lot. Therefore, four possible disciplines for the production/inspection flow exist (see Figure 4(b)). Figure 4(b) also shows the percentage of papers which consider these different disciplines. Although the Mixed production/batch inspection discipline is closer to the real condition of MMSs, the modelling and solving the complexity of that is greater.

\subsection{Inspection strategy}

Two different inspection strategies have been employed by the researchers in the literature: $100 \%$ or none inspection and Sampling inspection. In the first strategy some of the QCs are not inspected, and if it is decided to inspect a QC, all items are inspected. Sampling inspection means if it is decided to inspect a QC, a sample of items is inspected. Figure 4(c) illustrates the percentage of papers which consider these two different strategies. Although using the Sampling inspection is more practical in high rate production systems, it is difficult to be considered because the other parameters 


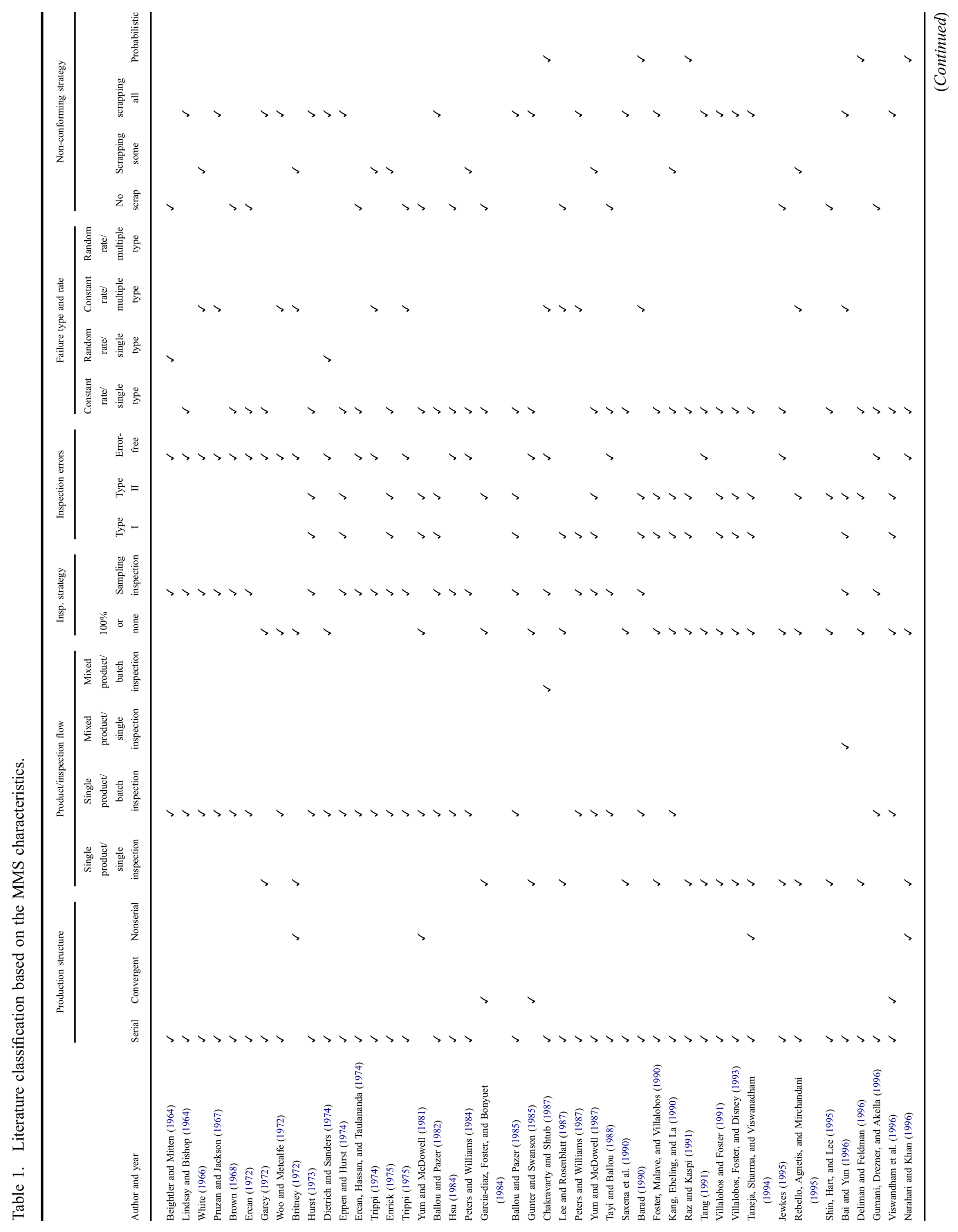




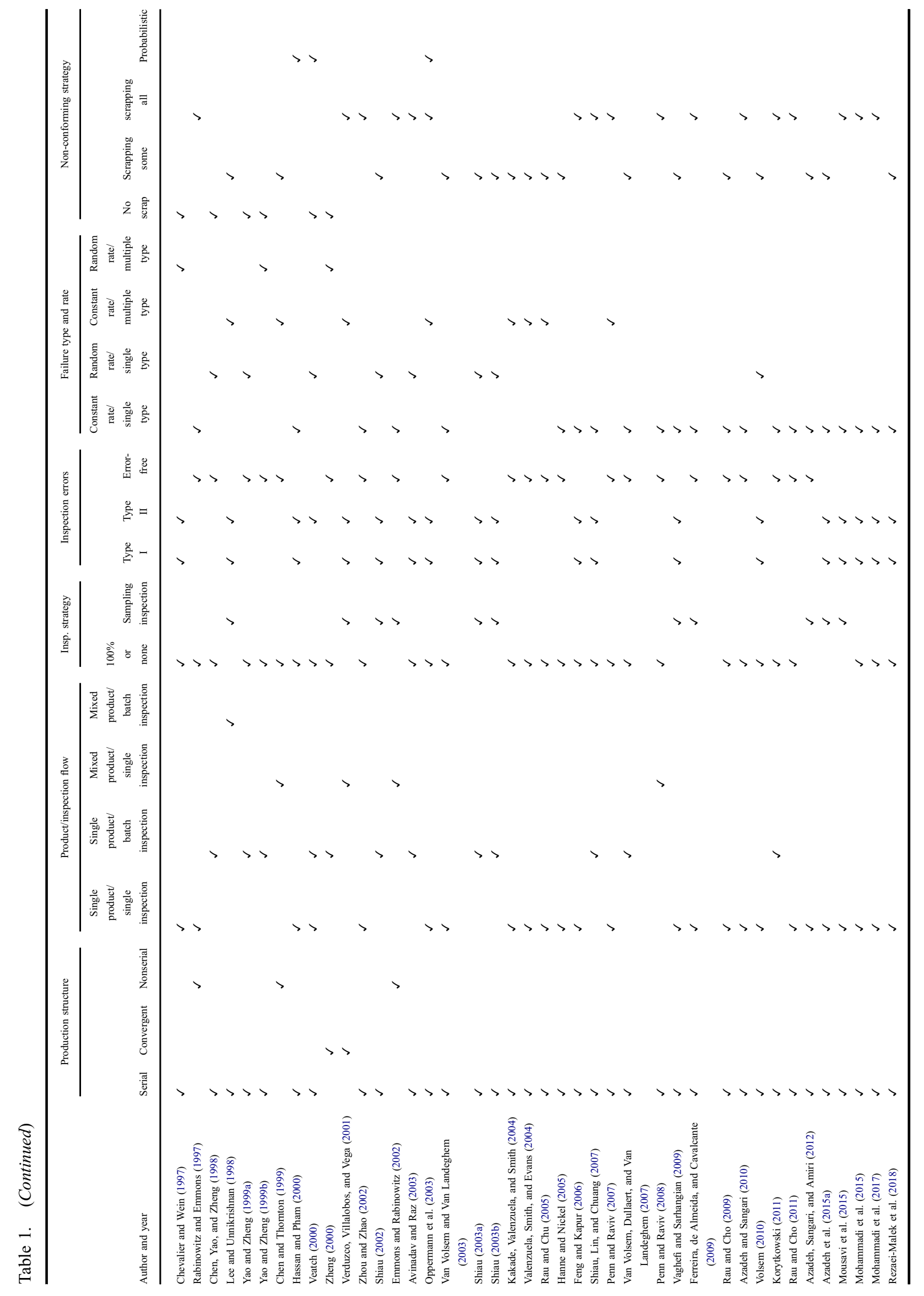




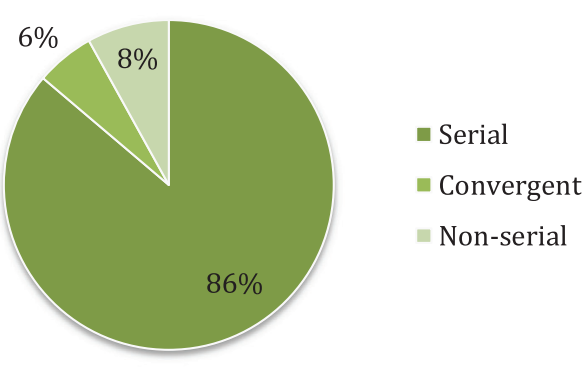

(a) Production structure

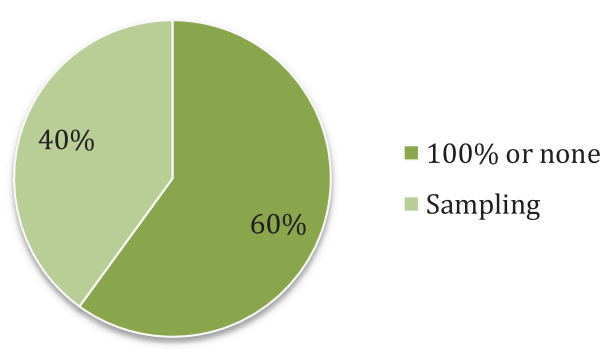

(c) Inspection type
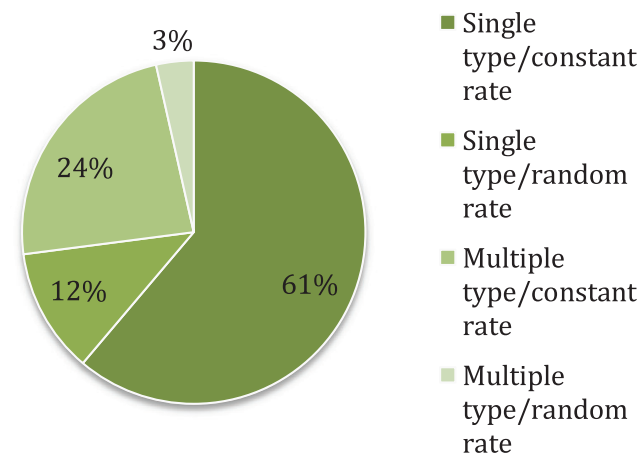

(e) Defective type in the system and defect rate at the stage

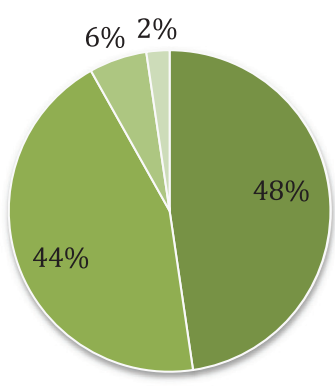

$$
\begin{aligned}
& \text { ■ingle } \\
& \text { Prod./Single } \\
& \text { Insp. } \\
& \text { — Single } \\
& \text { Prod./Batch } \\
& \text { Insp. } \\
& \text { Mixed } \\
& \text { Prod./Single } \\
& \text { Insp. } \\
& \text { Mixed } \\
& \text { Prod./Batch } \\
& \text { Insp. }
\end{aligned}
$$

(b) Production/Inspection flow

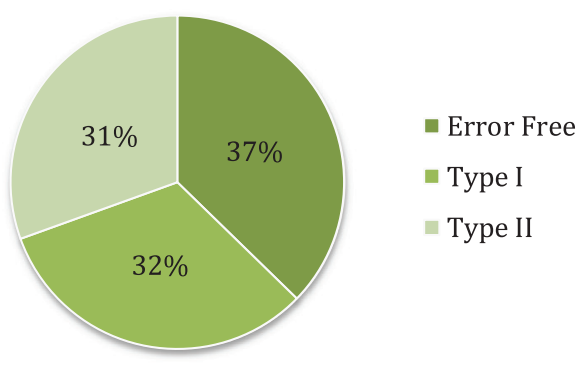

(d) Inspection error

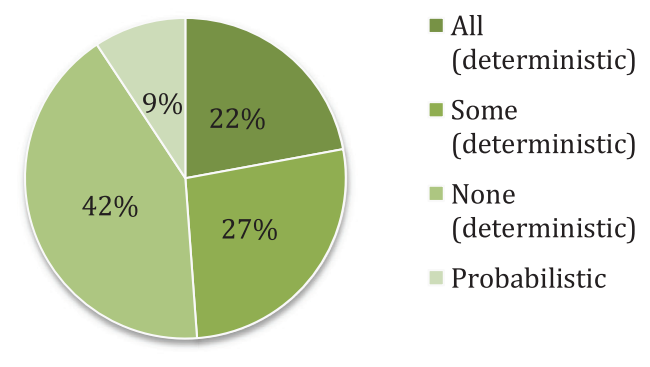

(f) Nonconforming strategies

Figure 4. Percentage of papers which considered different assumptions.

of this strategy (e.g. sample size) need to be determined simultaneously in the optimisation framework and this great number of decision variables increases the solution complexity of the problem.

\subsection{Inspection errors}

There are two types of errors that may happen during a part quality inspection activity:

(1) Error type I: occurs when a conforming item is classified wrongly as a non-conforming one.

(2) Error type II: happens when a non-conforming item is classified wrongly as a conforming one.

The Error-Free assumption for the inspection activity is unrealistic, but a considerable number of works considered the inspection activities free of any error (see Figure 4(d)). 


\subsection{Failure rate and type}

A failure rate of a manufacturing stage is the proportion of defects to all the produced items. In the literature, a certain constant failure rate for each stage has been assumed in some works, whereas others have assumed either a plausible range of a failure rate or random failure under a specific distribution. In addition, two single and multiple failure types have been considered by the authors. Actually, each QC is related to a single or multiple failure modes. In a case of a single failure type for a specific QC, the QC will not be realised properly if its related failure mode is active. Similarly, for the multiple failure types, the QC will not be realised appropriately if at least one of its related failure modes is active. In this regard, for the multiple failure types, a vector of failure rates is associated with multiple failure modes (Mandroli, Shrivastava, and Ding 2006). It is notable that each manufacturing stage may contain more than one failure mode. In conclusion, as shown in Figure 4(e), four potential combinations exist while a few papers only considered the Multiple type/random rate condition.

\subsection{Non-conforming strategy}

When inspection recognised an item as a non-conforming product, four possible actions can be done for it. The item can be reworked, repaired, replaced or scrapped. The decision about the appropriate action depends on the associated cost and knowledge of whether the non-conformity is reparable/reworkable or not. In this regard, a deterministic or probabilistic level of scrapping for non-conforming parts has been assumed by researchers. In the deterministic level, for a given type of non-conformity, the scrapping level is given as one of the three different possibilities: all, none, or some of the non-conforming items are scrapped. On the other side, others have assumed a probabilistic level which means that a non-conforming item is scrapped with a certain probability, so some of the items may have a chance to be reworked, repaired or replaced (Mohammadi 2015). According to the above-mentioned explanations, the non-conforming strategy is divided into four different subcategories as shown in Figure 4(f).

\section{Methodology characteristics}

According to the vast review of the PQIP literature, almost all of the studies have dealt with the problem through an optimisation formulation. In the following subsections, first, different kinds of the considered objective functions are elaborated, and then three necessary parts of an optimisation formulation as (i) constraint, (ii) uncertainty approach and (iii) solution approach are addressed. Table 2 illustrates the features of the literature regarding these optimisation characteristics.

\subsection{Objective functions}

Minimisation of the total expected cost is the most common form of objective function in the literature. Total cost generally includes different cost component as production, inspection and failure costs. The failure cost itself consists of internal and external cost. When non-conforming products are found before shipment to customer(s), it poses an internal cost to the system. This cost is specially related to the costs of reworking, repairing, replacing and scrapping a non-conforming product. A manufacturer undergoes the external failure costs when a defective product has been received by customer(s). These costs may be certain compensation or the lost sales and goodwill. The inspection cost contains two fixed and variable costs. The fixed inspection cost is related to a fixed amount of capital for preparing inspection tools and the variable cost directly depends on the frequency and number of inspected items. The variable inspection cost has often been assumed as a linear function, in which, the total variable inspection cost is the number of items inspected multiplied by the variable inspection cost per item (Mohammadi 2015). There are just two works, which have treated this cost as a non-linear function (see e.g. Ballou and Pazer 1985; Britney 1972). Regarding the current literature, there is no work which concurrently considers the non-linear form of variable inspection cost, fixed inspection cost and internal failure cost (i.e. scrap, rework, repair and replace).

Another common form of the objective function is expected unit cost. However, there are different ways to determine the units (see Figure 5(d)). Some papers have computed the expected unit cost as total cost divided by the number of input items (i.e. total cost/input items). The other versions are dividing the total cost by a number of outputs and dividing the total cost by the number of conforming outputs (i.e. total cost/output items or total cost/conforming output items).

There are only a few authors considering maximisation formulations in their studies. The maximisation objectives have mainly proposed in inspection scheduling problems besides to classical PQIP problem. To the best of our 


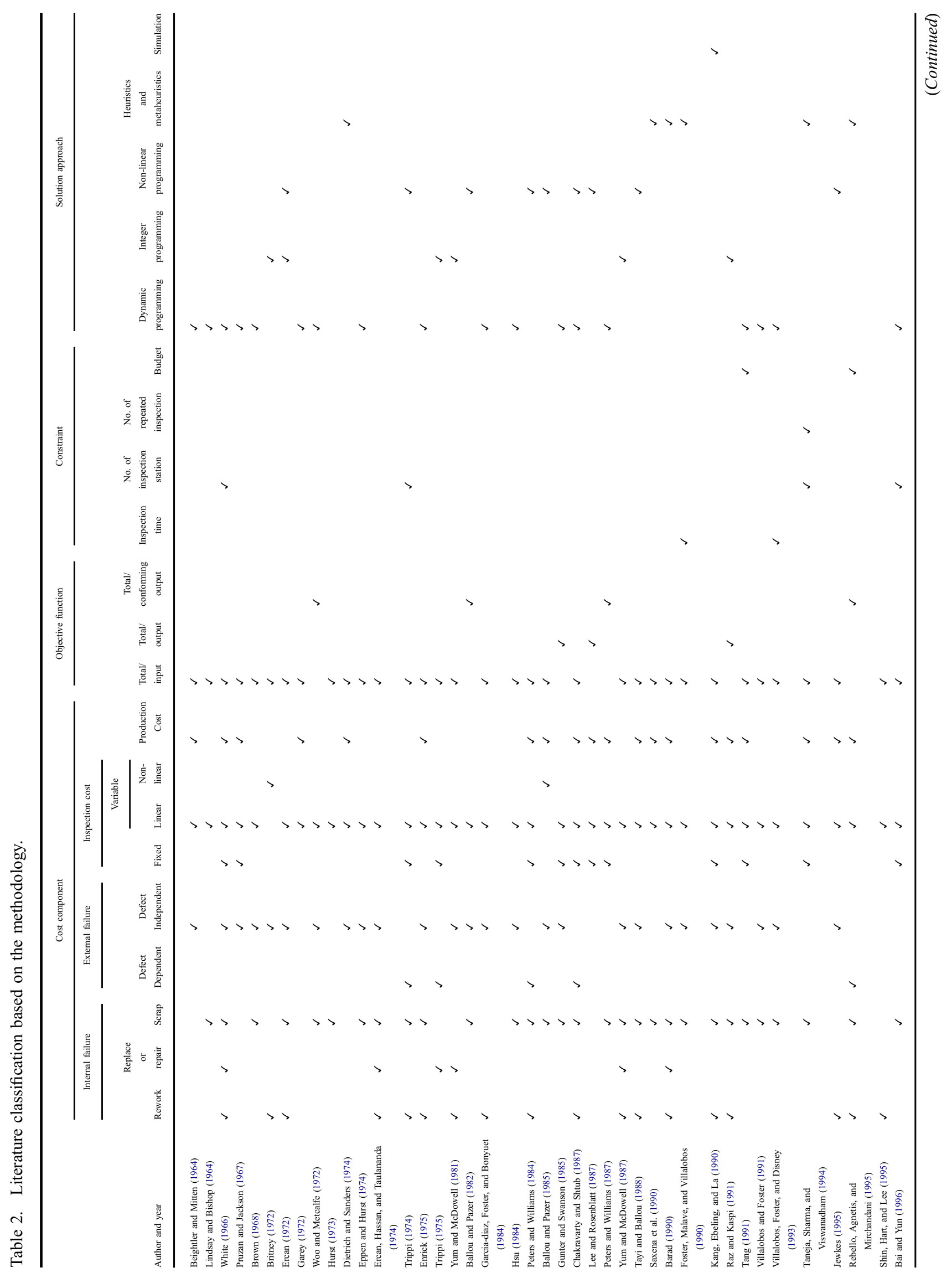




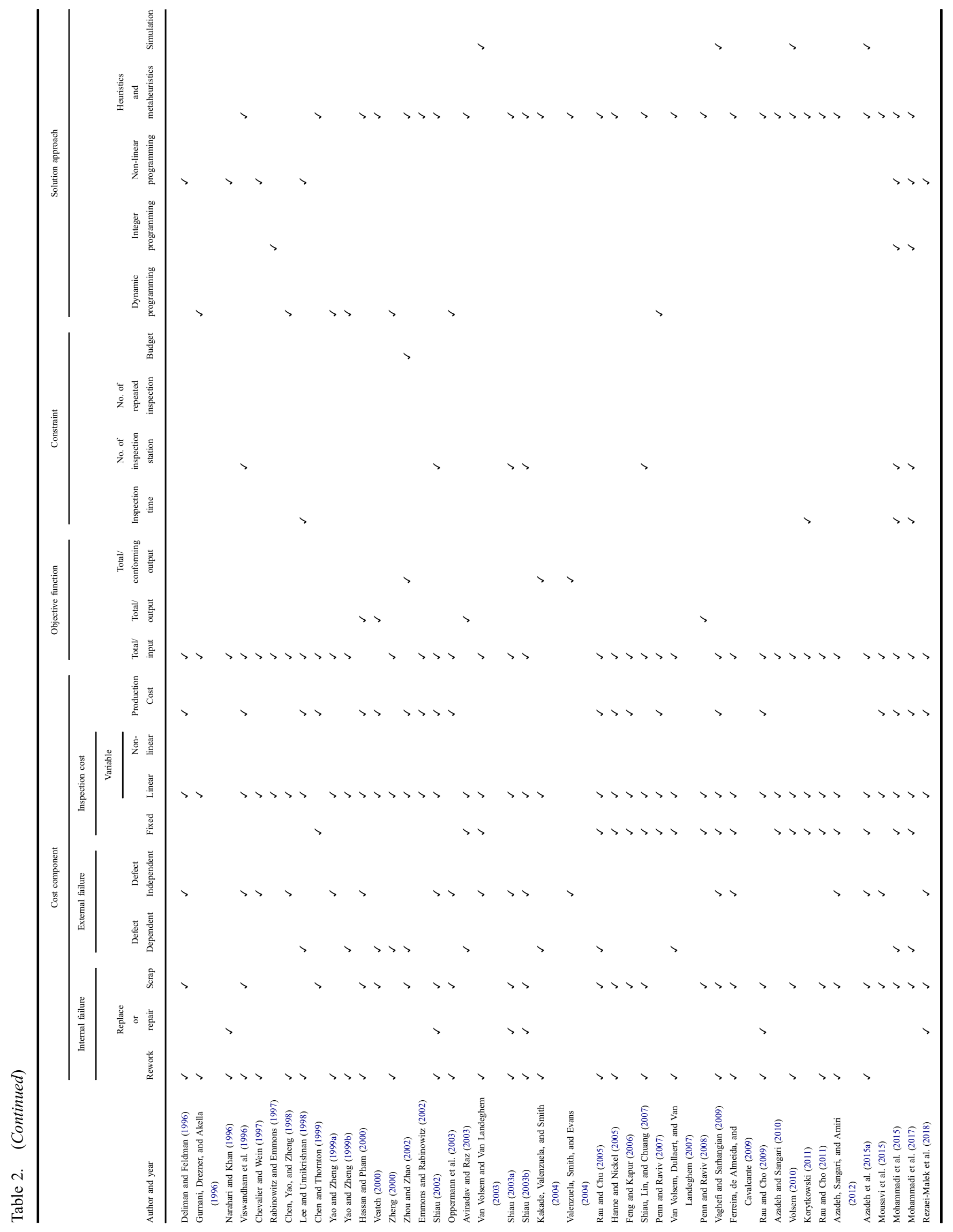




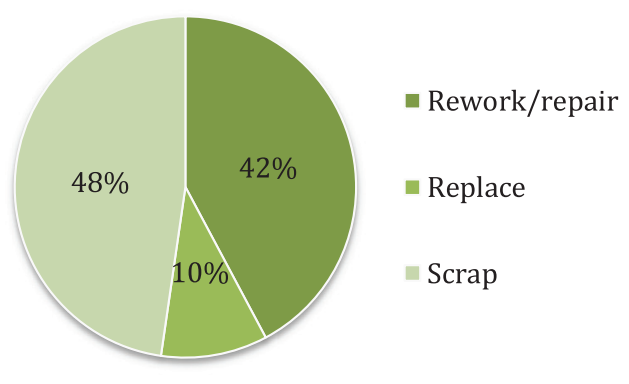

(a) Internal failure cost

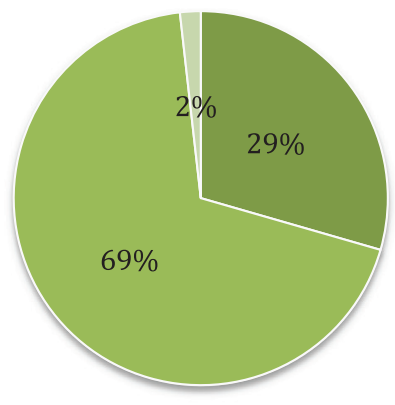

(c) Inspection cost
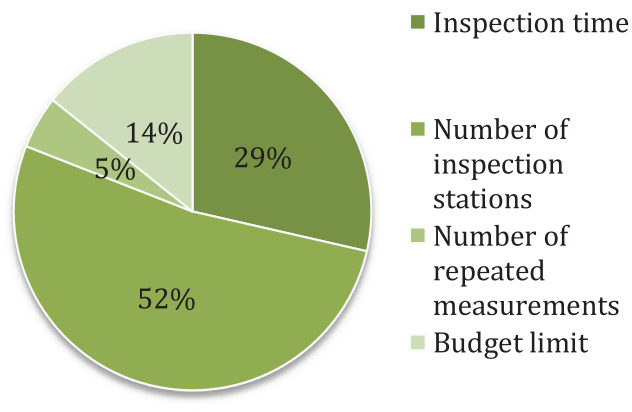

(e) Additional constraints

- Fixed cost cost

Nonlinear variable cost

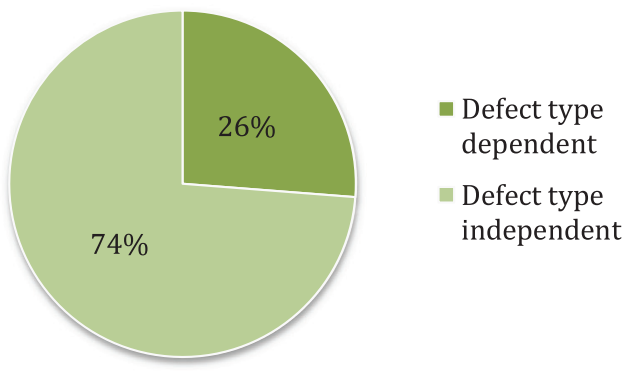

(b) External failure cost

- Linear variable

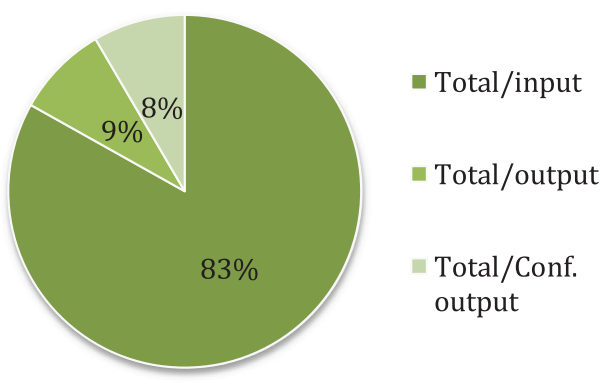

(d) Form of expected unit cost

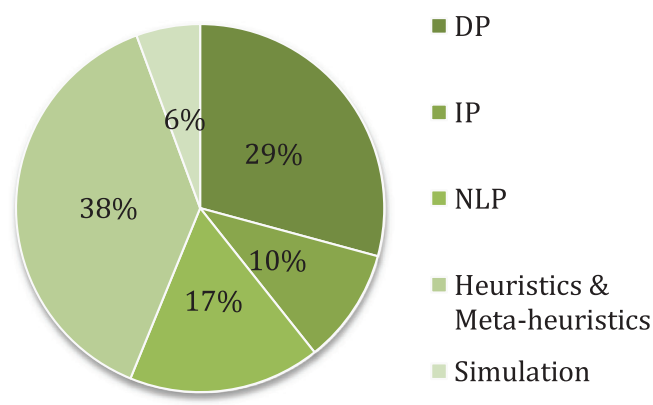

(f) Optimization method

Figure 5. Percentage of papers considered different methodology characteristics.

knowledge, no study has considered minimising total manufacturing time. In addition, there is a lack of applying multiobjective models in the current PQIP literature. In this respect, Mohammadi et al. (2017) developed a bi-objective mixed-integer programming model for the PQIP problem. The objectives were the minimisation of (1) internal and (2) external costs. They solved the presented model by employing a meta-heuristic algorithm, namely differential evolution (DE) algorithm. For approaching to the real situation of MMSs, where they face to the conflict objectives for optimising their systems, developing the multi-objective mathematical models which simultaneously optimise several conflict objectives is an excellent research direction for future in this field. For instance, when the quality of the system is maximised through employing more inspection stations, the production cycle time is increased. Hence, developing a new bi-objective model to establish a trade-off between these two conflict objectives seems interesting and practical. 


\subsection{Constraints}

The constraints in the typical PQIP problem are mostly associated with the different types of production structure and non-conforming strategy. Moreover, other constraints have been imposed to the optimisation formulation. For example, some of them are: limitations on inspection time, number of inspection and rework stations, number of inspection repetition, the budget for production and inspection activities, required places that an inspection can be done, and minimum throughput or production capacity. Figure 5(e) illustrates the percentage of papers which considered different constraints.

Other constraints in the developed optimisation formulation could be the dependency between different QCs that require being inspected. For instance, two QCs must be inspected in parallel or vice versa. In addition to QCs dependency, in some situations, there are dependent production stages, and there is no possibility to stop a particular stage to inspect a QC and you need to wait for the following operation(s) to be completed (Mirdamadi 2014; Mohammadi 2015). There are other applicable and realistic constraints in the domain of PQIP problem that have not considered yet such as the limited capacity of operating machines, waiting time for inspection and inspection tools to treat the items.

\subsection{Optimisation under uncertainty}

The PQIP problem inherently contains different sources of uncertainty. Accordingly, the necessity for consideration of associate uncertain parameters and obtaining a robust solution has been implied by most of the researchers, and it should be extended more. One of the main sources of uncertainty in this problem refers to the condition of production stages for processing items in conformity with specification region. This uncertain condition results in the uncertainty of the failure production rate parameter. In this regard, many works considered the random failure rate in a probabilistic manner (see Table 1). They assumed a specific probability distribution (e.g. Bernoulli distribution) for this parameter. By the above-mentioned source of uncertainty, the proportion of non-conforming items which is repairable, reworkable or need to be scrapped or replaced, is uncertain. This uncertain data has been also treated as a probabilistic non-conforming strategy in the literature (See Table 1). Regarding the uncertainty about inspection tools and inspection operators, Error type I and Error type II have been considered probabilistically by the majority of researchers (see Table 1). Beside these uncertainties which are rooted in the internal reasons, there are the other uncertainties that are related to the uncertain external condition such as price fluctuations (Azadeh et al. 2015). Azadeh et al. (2015) described the cost components (i.e. inspection, rework and penalty of defects shipment) by applying of fuzzy numbers. They proposed a fuzzy model for the problem and converted it into an equivalent auxiliary crisp model by employing the Jimenez's definition of expected value. Mohammadi et al. (2017) considered alteration ranges for the production and inspection times, errors type I and II of the inspection activities, dispersion and misadjustment of the production processes, and developed a global robust model based on optimising the expected value and variance of the objective function in the form of the Taguchi method. Regarding these recent works, it would be an excellent research direction to propose an aggregate approach (e.g. a robust possibilistic programming approach) to make use of the advantages of the fuzzy and robust approaches for simultaneously considering uncertainties related to the internal and external reasons.

\subsection{Solution approaches}

The researchers have developed a wide variety of solution approaches for solving the PQIP problem. In the most cases, they derived a non-linear total cost function while some of the decision variables (e.g. opening an inspection station) can only have integer values. This transforms the problem to a non-linear and integer programming problem. Besides the classical optimisation algorithms, iterative gradient searches, and experiment-based response surface methodologies, the researchers have used the gradient-based methods for continuous optimisation in the non-linear programming (NLP) (Mandroli, Shrivastava, and Ding 2006). For the integer programming, the discrete optimisation approaches such as those using the branch-and-bound technique are applied (Raz and Kaspi 1991).

Because the multi-stage structure of manufacturing systems can well be considered by stages and states of the dynamic programming (DP) models, $29 \%$ of the 89 reviewed papers applied DP and made this approach as the most used one (see Figure 5(f)). However, DP becomes quite impractical as the set of possibilities (i.e. possible combinations) increases exponentially (Mandroli, Shrivastava, and Ding 2006; Shetwan, Vitanov, and Tjahjono 2011).

Indeed, a huge restriction of these approaches is their incapability of solving medium and large size problems due to the requirement of high computational time and memory. This limitation results in usage of heuristic and meta-heuristic algorithms in this domain, such as simulated annealing (SA) and genetic algorithm (GA). They obtain near-optimal solutions in considerable low computational time (Mohammadi 2015). Mohammadi et al. (2017) applied a differential 
evolution (DE) algorithm, which provides promising results in comparison with SA and GA for solving the mixed-integer linear programming model.

Another optimisation approach is simulation; however, this method just investigates a limited number of production scenarios for optimisation. Considering the current literature, no study proposes an exact solution method to large size instances. In this regard, developing decomposition methods (e.g. Benders decomposition methods) to solve large size mixed-integer programming models can be a huge contribution to this area. In addition, employing some newly developed meta-heuristic algorithms, such as Fireworks and Cuckoo Search and comparing to the conventional SA, GA and $\mathrm{DE}$ algorithms regarding computational capability can be interesting as a future research direction.

\section{Integrated optimisation}

Production, quality and maintenance are three significant aspects of each manufacturing system and are interrelated problems (Ben-Daya and Rahim 2001). Figure 6 proposed by Ben-Daya and Duffuaa (1995) shows their interconnectivities in a manufacturing system. The link from Production to Maintenance infers that the employed equipment in Production needs some maintenance activities to be restored to a good condition. The link from Maintenance to Production implies that maintenance activities impact on the capacity of Production. The link between Production and Quality means that if Production works in the right way, it can produce the high-quality products. And the link between Maintenance and Quality implies that if the equipment is maintained in good condition, they can operate without any fault.

The aim of this section is not to review the papers, which proposed integrated planning for quality, production and maintenance. Since the main problem of this review paper is the PQIP problem, the papers that are reviewed here are those whose principal problem is the PQIP and that have tried to incorporate the production and maintenance issues into it. Indeed, there are a few works in the literature which incorporated production logistic decisions such as optimum lot size (Tayi and Ballou 1988), production rate (Gunter and Swanson 1985; Penn and Raviv 2007, 2008), sequence of operations (Raz and Kaspi 1991), inspection scheduling (Emmons and Rabinowitz 2002), inspection resource assignment (Shiau 2002), assignment of operations to operators (Hanne and Nickel 2005) and process scheduling (Shiau, Lin, and Chuang 2007) into the PQIP problem. On the other side, the determination of a part quality inspection plan in the MMS should be considered regarding the impacts of the maintenance activities. When inspection cost is considerable, it is reasonable to inspect less frequently during the time the operation stage is in healthier states (it is capable to processed high-quality items), and, more frequently as time passes and/or the operation stage degrades (Rezaei-Malek et al. 2017). Rezaei-Malek et al. (2018) presented a mixed-integer mathematical model for the integrated planning of the part quality inspection and preventive maintenance activities while production stages are deteriorating. In this respect, defining and solving an integrated planning problem which simultaneously determines the optimum plan of part quality inspection, maintenance and production is an interesting research direction by Industry 4.0.

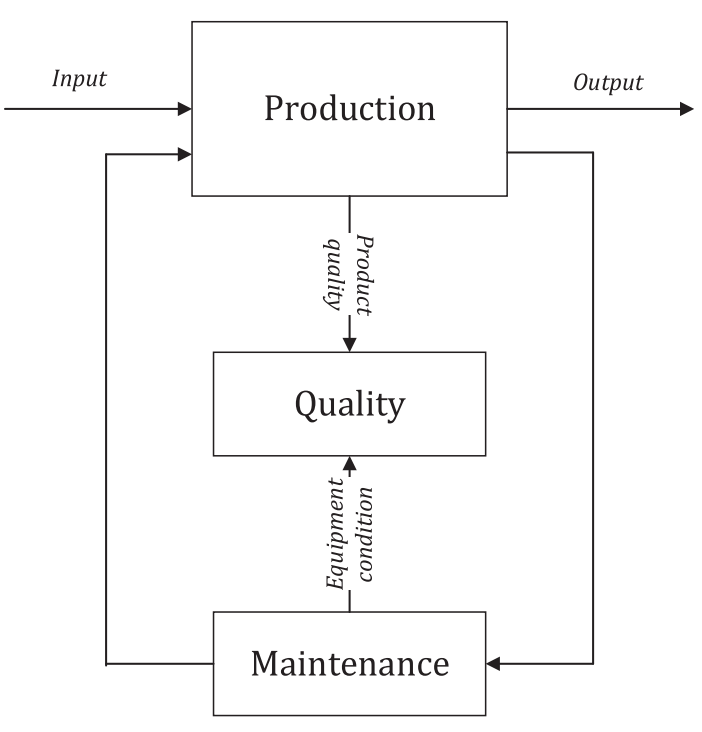

Figure 6. Relation of production, maintenance and quality (Ben-Daya and Duffuaa 1995). 


\section{Conclusions and future research directions}

In the framework of a quality assurance programme, the PQIP is a significant decision problem, which all the MMSs are dealing with. Indeed, a proper part quality inspection plan not only avoids delivering non-conforming products to customer(s), but also increases the efficiency of the MMS by decreasing waste of time and material.

In this review paper, the existing research works on the PQIP optimisation problem have been reviewed from the viewpoint of the MMS characteristics as well as the modelling and solution methodologies. In addition, the literature has been investigated regarding the integrated optimisation of the part quality inspection with the maintenance and production planning. Based on the conducted review, some directions for future research based on recognised shortcomings in this field are provided in the following sections:

\subsection{MMS characteristics}

- Most of the existing research works have focused on the PQIP optimisation in serial production systems, while most of the actual production systems follow a combination of serial and non-serial structures.

- Few papers have investigated multi-product MMS with different quality characteristics, while most of the current production systems process contains different quality characteristics of multiple products.

- Incorporating the inspection tool selection problem into the classical PQIP makes the model more real and obtains more flexible inspection plan. So, manufacturers can apply inspection tools with higher precision and decrease the number of non-detected items that reach customers and consequently raise customer satisfaction (Mohammadi 2015). In addition, inspection tools with higher reliability can be utilised.

- Considering machine selection decision at the same time as PQIP decisions causes that manufacturer can purchase machines with high capability to obtain high-quality level for essential design characteristics.

\subsection{Methodology characteristics}

- Developing more multi-objective PQIP models, which concurrently consider multiple conflict objectives. For example, development of a new bi-objective model to establish a trade-off between production cycle time, average outgoing quality and total cost seems so interesting and practical.

- By considering time as an objective, one significant issue that comes up is waiting time for the WIP items. Different items must wait before each processing or inspection station to receive services. These waiting times should be analysed in the final decisions.

- Since MMSs are stochastic in nature and are impacted by different unpredictable environmental factors, machines and inspection tools are subject to disruption. Any breakdown in the production system not only increases the manufacturing cost, but also significantly affects the quality of final products. Therefore, considering the reliability issue of a production system and investigating the effect of unreliable machines and inspection tools on the final PQIP could be an interesting research direction.

- Almost all the authors have ignored manufacturing constraints in their studies. Some of these constraints could be the capacity of machines and inspection tools, an upper bound for total production time, low capital for initial investment and limited places for performing inspections, and so on. Considering these constraints provides more real and applicable inspection plans.

- Most of the existing research works have not taken the uncertainty of system into account. These uncertainties are of different parameters such as production and inspection costs, production and inspection times, production capability, errors type I and II and lots of other related parameters. Taking these uncertainties into account provides a more realistic optimisation of inspection plans and leads to more appropriate solutions for inspection planning systems. For instance, it would be an excellent research direction to propose an aggregate approach (e.g. a robust possibilistic programming approach) to make use of the advantages of the fuzzy and robust approaches for concurrently incorporating uncertainties related to the internal and external failure reasons into an optimisation model.

- Developing efficient decomposition algorithms to achieve exact solutions is also another gap in the literature for solving large size problems.

- Considering the impact of different maintenance activities on the optimum part quality inspection plan and accordingly developing an integrated optimum plan for the inspection, maintenance and production. 
- Recently, some researchers have tried to design manufacturing systems which are psychologically consistent (Azadeh et al. 2015, 2017; Rezaei-Malek et al. 2017). Since operators play critical roles in the inspection process in the most of manufacturing systems, it would be interesting if one can incorporate this new concept and its impact on the inspection accuracy into the PQIP problem.

\section{Acknowledgements}

The authors would like to acknowledge France embassy in Iran and Campus France, the French national agency for the promotion of higher education, international student services and international mobility, for their financial support under the scholarship number 906221A.

\section{Disclosure statement}

No potential conflict of interest was reported by the authors.

\section{ORCID}

Mohammad Rezaei-Malek (D) http://orcid.org/0000-0002-0772-2255

Mehrdad Mohammadi (D) http://orcid.org/0000-0002-3683-5646

Jean-Yves Dantan (D) http://orcid.org/0000-0002-0491-8391

Ali Siadat (D) http://orcid.org/0000-0002-8406-1892

Reza Tavakkoli-Moghaddam (D) http://orcid.org/0000-0002-6757-926X

\section{References}

Avinadav, T., and T. Raz. 2003. "Economic Optimization in a Fixed Sequence of Unreliable Inspections." Journal of the Operational Research Society 54 (6): 605-613.

Azadeh, A., and M. S. Sangari. 2010. "A Metaheuristic Method for Optimising Inspection Strategies in Serial Multistage Processes." International Journal of Productivity and Quality Management 6 (3): 289-303.

Azadeh, A., M. S. Sangari, and A. S. Amiri. 2012. "A Particle Swarm Algorithm for Inspection Optimization in Serial Multi-stage Processes." Applied Mathematical Modelling 36 (4): 1455-1464.

Azadeh, A., M. S. Sangari, E. Sangari, and S. Fatehi. 2015. "A Particle Swarm Algorithm for Optimising Inspection Policies in Serial Multistage Production Processes with Uncertain Inspection Costs." International Journal of Computer Integrated Manufacturing 28 (7): 766-780.

Azadeh, A., M. Rezaei-Malek, F. Evazabadian, and M. Sheikhalishahi. 2015. "Improved Design of CMS by Considering Operators Decision-making Styles.” International Journal of Production Research 53 (11): 3276-3287.

Azadeh, A., M. Ravanbakhsh, M. Rezaei-Malek, M. Sheikhalishahi, and A. Taheri-Moghaddam. 2017. "Unique NSGA-II and MOPSO Algorithms for Improved Dynamic Cellular Manufacturing Systems Considering Human Factors." Applied Mathematical Modelling 48: 655-672.

Bai, D., and H. Yun. 1996. "Optimal Allocation of Inspection Effort in a Serial Multi-stage Production System." Computers \& Industrial Engineering 30 (3): 387-396.

Ballou, D. P., and H. L. Pazer. 1982. "The Impact of Inspector Fallibility on the Inspection Policy in Serial Production Systems." Management Science 28 (4): 387-399.

Ballou, D. P., and H. L. Pazer. 1985. "Process Improvement versus Enhanced Inspection in Optimized Systems." International Journal of Production Research 23 (6): 1233-1245.

Barad, M. 1990. “A Break-even Quality Level Approach to Location of Inspection Stations in a Multi-stage Production Process.” International Journal of Production Research 28 (1): 29-45.

Beightler, C. S., and L. G. Mitten. 1964. "Design of an Optimal Sequence of Interrelated Sampling Plans." Journal of the American Statistical Association 59 (305): 96-104.

Ben-Daya, M., and S. O. Duffuaa. 1995. "Maintenance and Quality: The Missing Link.” Journal of Quality in Maintenance Engineering 1 (1): 20-26.

Ben-Daya, M., and M. Rahim. 2001. "Integrated Production, Quality and Maintenance Models, an Overview." In Integrated Models in Production Planning, Inventory, Quality and Maintenance, edited by M. Rahim and M. Ben-Daya, 3-28. New York: Kluwer Academic .

Britney, R. R. 1972. “Optimal Screening Plans for Nonserial Production Systems.” Management Science 18 (9): $550-559$. 
Brown, E. D. 1968. Some Mathematical Models of Inspection along a Production Line (No. TR-36). Massachusetts Inst of Tech Cambridge Operations Research Center.

Chakravarty, A. K., and A. Shtub. 1987. "Strategic Allocation of Inspection Effort in a Serial, Multi-product Production System." IIE Transactions 19 (1): 13-22.

Chen, T. J., and A. C. Thornton. 1999. Quantitative Selection of Inspection Plans. Proceedings of the 1999 ASME Design Engineering Technical Conferences. New York: American Society of Mechanical Engineers.

Chen, J., D. D. Yao, and S. Zheng. 1998. "Quality Control for Products Supplied with Warranty.” Operations Research 46 (1): $107-$ 115.

Chevalier, P. B., and L. W. Wein. 1997. "Inspection for Circuit Board Assembly.” Management Science 43 (9): $1198-1213$.

Colledani, M., T. Tolio, A. Fischer, B. Iung, G. Lanza, R. Schmitt, and J. Váncza. 2014. "Design and Management of Manufacturing Systems for Production Quality.” CIRP Annals 63 (2): 773-796.

Deliman, N. C., and R. M. Feldman. 1996. "Optimization of Process Improvement and Inspection Location for Serial Manufacturing." International Journal of Production Research 34 (2): 395-405.

Dietrich, D. L., and J. L. Sanders. 1974. “A Bayesian Quality Assurance Model for a Multi-stage Production Process.” ASQC Technical Conference Transactions, 338-348. Milwaukee, WI: American Society for Quality Control.

Emmons, H., and G. Rabinowitz. 2002. "Inspection Allocation for Multi-stage Deteriorating Production Systems." IIE Transactions 34 (12): 1031-1041.

Enrick, N. L. 1975. “Towards Optimization of Inspection Allocation Part I and II.” Industrial Management 17 (3): 7-11.

Eppen, G. D., and E. G. Hurst Jr. 1974. “Optimal Location of Inspection Stations in a Multistage Production Process.” Management Science 20 (8): 1194-1200.

Ercan, S. S. 1972. "Systems Approach to the Multistage Manufacturing Connected-unit Situation." Naval Research Logistics Quarterly 19 (3): 493-500.

Ercan, S. S., M. Z. Hassan, and A. Taulananda. 1974. "Cost Minimizing Single Sampling Plans with AIQL and AOQL Constraints." Management Science 20 (7): 1112-1121.

Feng, Q., and K. C. Kapur. 2006. "Economic Design of Specifications for 100\% Inspection with Imperfect Measurement Systems." Quality Technology \& Quantitative Management 3 (2): 127-144.

Ferreira, R. J. P., A. T. de Almeida, and C. Cavalcante. 2009. "A Multi-criteria Decision Model to Determine Inspection Intervals of Condition Monitoring Based on Delay Time Analysis." Reliability Engineering and System Safety 94: 905-912.

Foster, J. W., C. O. Malave, and J. R. Villalobos. 1990. "Flexible Inspection within an Aggregated Information Environment." Computers \& Industrial Engineering 19 (1-4): 224-228.

Garcia-diaz, A., J. W. Foster, and M. Bonyuet. 1984. "Dynamic Programming Analysis of Special Multi-stage Inspection Systems." IIE Transactions 16 (2): 115-126.

Garey, M. R. 1972. “Optimal Test Point Selection for Sequential Manufacturing Processes.” Bell System Technical Journal 51 (1): 291-300.

Gunter, S. I., and L. A. Swanson. 1985. "Inspector Location in Convergent Production Lines.” International Journal of Production Research 23 (6): 1153-1169.

Gurnani, H., Z. Drezner, and R. Akella. 1996. "Capacity Planning under Different Inspection Strategies." European Journal of Operational Research 89 (2): 302-312.

Hanne, T., and S. Nickel. 2005. "A Multiobjective Evolutionary Algorithm for Scheduling and Inspection Planning in Software Development Projects.” European Journal of Operational Research 167: 663-678.

Hassan, A., and D. T. Pham. 2000. "Optimisation of Inspection Stations by Using Simulated Annealing." International Journal for Manufacturing Science and Technology 2: 59-65.

Hsu, J. I. S. 1984. "A Hybrid Inspection System for the Multistage Production Process." International Journal of Production Research 22 (1): 63-70.

Hurst, E. G. 1973. "Imperfect Inspection in a Multistage Production Process." Management Science 20 (3): 378-384.

Jewkes, E. M. 1995. "Optimal Inspection Effort and Scheduling for a Manufacturing Process with Repair." European Journal of Operational Research 85: 340-351.

Kakade, V., J. F. Valenzuela, and J. S. Smith. 2004. “An Optimization Model for Selective Inspection in Serial Manufacturing Systems." International Journal of Production Research 42 (18): 3891-3909.

Kang, K., K. A. Ebeling, and S. La. 1990. "The Optimal Location of Inspection Stations Using a Rule-based Methodology." Computers \& Industrial Engineering 19 (1-4): 272-275.

Korytkowski, P. 2011. "A Genetic Algorithm with Tournament Selection for Optimising Inspection Allocation in Multiproduct Multistage Production Systems." International Journal of Simulation and Process Modelling 6 (3): 238-244.

Lee, H. L., and M. J. Rosenblatt. 1987. "Simultaneous Determination of Production Cycle and Inspection Schedules in a Production System." Management Science 33: 1125-1136.

Lee, J., and S. Unnikrishnan. 1998. "Planning Quality Inspection Operations in Multistage Manufacturing Systems with Inspection Errors.” International Journal of Production Research 36 (1): 141-156.

Lindsay, G. F., and A. B. Bishop. 1964. "Allocation of Screening Inspection Effort - Dynamic Programming Approach." Management Science 10 (2): 343-352. 
Mandroli, S. S., A. K. Shrivastava, and Y. Ding. 2006. "A Survey of Inspection Strategy and Sensor Distribution Studies in Discretepart Manufacturing Processes." IIE Transactions 38 (4): 309-328.

Mirdamadi, S.2014. "Système d'aide à la décision pour la génération des processus d'inspection par la fédération des expertises métier [Decision Support System for the Generation of Inspection Processes by the Federation of Business Expertises]." Doctoral dissertation, Institut d'Optique Graduate School.

Mohammadi, M. 2015. “A Multi-objective Optimization Framework for an Inspection Planning Problem under Uncertainty and Breakdown.” Mechanical Engineering [physics.class-ph]. Ecolenationale supérieure d'arts et métiers - ENSAM. NNT: 2015ENAM0055.

Mohammadi, M., A. Siadat, J. Y. Dantan, and R. Tavakkoli-Moghaddam. 2015. "Mathematical Modelling of a Robust Inspection Process Plan: Taguchi and Monte Carlo Methods.” International Journal of Production Research 53 (7): $2202-2224$.

Mohammadi, M., J. Y. Dantan, A. Siadat, and R. Tavakkoli-Moghaddam. 2017. "A Bi-objective Robust Inspection Planning Model in a Multi-stage Serial Production System." International Journal of Production Research. doi:10.1080/ 00207543.2017 .1363425 .

Montgomery, D. C. 2009. Introduction to Statistical Quality Control. New York: John Wiley.

Mousavi, S. M., S. Mirdamadi, A. Siadat, J. Dantan, and R. Tavakkoli-Moghaddam. 2015. "An Intuitionistic Fuzzy Grey Model for Selection Problems with an Application to the Inspection Planning in Manufacturing Firms." Engineering Applications of Artificial Intelligence 39: 157-167.

Narahari, Y., and L. M. Khan. 1996. "Modeling Reentrant Manufacturing Systems with Inspection Stations." Journal of Manufacturing Systems 15 (6): 367-378.

Oppermann, M., W. Sauer, H. Wohlrabe, and T. Zerna. 2003. "New Quality Cost Models to Optimize Inspection Strategies." IEEE Transactions on Electronics Packaging Manufacturing 26 (4): 328-337.

Penn, M., and T. Raviv. 2007. "Optimizing the Quality Control Station Configuration.” Naval Research Logistics 54 (3): $301-314$.

Penn, M., and T. Raviv. 2008. “A Polynomial Time Algorithm for Solving a Quality Control Station Configuration Problem.” Discrete Applied Mathematics 156 (4): 412-419.

Peters, M. H., and W. W. Williams. 1984. "Location of Quality Inspection Stations: An Experimental Assessment of Five Normative Heuristics." Decision Sciences 15 (3): 389-408.

Peters, M. H., and W. W. Williams. 1987. "Economic Design of Quality Monitoring Efforts for Multi-stage Production Systems.” IIE Transactions 19 (1): 81-87.

Pruzan, P. M., and J. R. Jackson. 1967. “A Dynamic Programming Application in Production Line Inspection.” Technometrics 9 (1): 73-81.

Rabinowitz, G., and H. Emmons. 1997. "Optimal and Heuristic Inspection Schedules for Multi-stage Production Systems.” IIE Transactions 29 (12): 1063-1071.

Rau, H., and K. H. Cho. 2009. "Genetic Algorithm Modeling for the Inspection Allocation in Reentrant Production Systems." Expert Systems with Applications 36 (8): 11287-11295.

Rau, H., and K. H. Cho. 2011. "Particle Swarm Optimization with Mutation for the Inspection Allocation in Reentrant Production Systems." Proceedings of the International Conference on Machine Learning and Cybernetics (ICMLC), Vol. 3, $1025-1030$. Guilin, July 10-13.

Rau, H., and Y. H. Chu. 2005. "Inspection Allocation Planning with Two Types of Workstation: WVD and WAD." The International Journal of Advanced Manufacturing Technology 25: 947-953.

Raz, T . 1986. "A Survey of Models for Allocating Inspection Effort in Multistage Production Systems.” Journal of Quality Technology. 18 (4) : 239-247.

Raz, T., and M. Kaspi. 1991. "Location and Sequencing of Imperfect Inspection Operations in Serial Multi-stage Production Systems.” International Journal of Production Research 29 (8): 1645-1659.

Rebello, R., A. Agnetis, and P. B. Mirchandani. 1995. "Specialized Inspection Problems in Serial Production Systems." European Journal of Operational Research 80: 277-296.

Rezaei-Malek, M., R. Tavakkoli-Moghaddam, A. Siadat, and J.-Y. Dantan. 2017. Integrated Preventive Maintenance and Inspection Planning in a Deteriorating Serial Multi-stage Manufacturing System. Proceedings of the 7th IESM Conference, Vol. 2, 352357. Saarbrücken, October 11-13.

Rezaei-Malek, M., J. Razmi, R. Tavakkoli-Moghaddam, and A. Taheri-Moghaddam. 2017. "Towards a Psychologically Consistent Cellular Manufacturing System." International Journal of Production Research 55 (2): 492-518.

Rezaei-Malek, M., R. Tavakkoli-Moghaddam, A. Siadat, and J.-Y. Dantan. 2018. "A Novel Model for the Integrated Planning of Part Quality Inspection and Preventive Maintenance in a Linear-deteriorating Serial Multi-stage Manufacturing System." The International Journal of Advanced Manufacturing Technology. doi:10.1007/s00170-018-1751-1.

Saxena, S., C. M. Chang, H. B. Chow, and J. Lee. 1990. "Evaluation of Heuristics for Inspection Station Allocation in Serial Production Systems." Proceedings of the 22nd Conference on Winter Simulation, 919-922. New Orleans, LA, December 9-12.

Shetwan, A. G., V. I. Vitanov, and B. Tjahjono. 2011. "Allocation of Quality Control Stations in Multistage Manufacturing Systems." Computers \& Industrial Engineering 60 (4): 473-484.

Shiau, Y. R. 2002. "Inspection Resource Assignment in a Multistage Manufacturing System with an Inspection Error Model." International Journal of Production Research 40 (8): 1787-1806. 
Shiau, Y. R. 2003a. "Inspection Allocation Planning for a Multiple Quality Characteristic Advanced Manufacturing System." The International Journal of Advanced Manufacturing Technology 21 (7): 494-500.

Shiau, Y. R. 2003b. "Quick Decision-making Support for Inspection Allocation Planning with Rapidly Changing Customer Requirements." The International Journal of Advanced Manufacturing Technology 22 (9-10): 633-640.

Shiau, Y. R., M. H. Lin, and W. C. Chuang. 2007. "Concurrent Process/Inspection Planning for a Customized Manufacturing System Based on Genetic Algorithm.” The International Journal of Advanced Manufacturing Technology 33 (7-8): 746-755.

Shin, W. S., S. M. Hart, and H. F. Lee. 1995. "Strategic Allocation of Inspection Stations for a Flow Assembly Line: A Hybrid Procedure." IIE Transactions 27 (6): 707-715.

Taneja, M., S. M. Sharma, and N. Viswanadham. 1994. "Location of Quality-control Stations in Manufacturing Systems: A Simulated Annealing Approach.” Systems Practice 7 (4): 367-380.

Tang, C. S. 1991. "Designing an Optimal Production System with Inspection." European Journal of Operational Research 52 (1): $45-54$.

Tayi, G. K., and D. P. Ballou. 1988. “An Integrated Production-inventory Model with Reprocessing and Inspection.” International Journal of Production Research 26 (8): 1299-1315.

Trippi, R. R. 1974. “An On-line Computational Model for Inspection Resource Allocation.” Journal of Quality Technology 6: 167174.

Trippi, R. R. 1975. "The Warehouse Location Formulation as a Special Type of Inspection Problem.” Management Science 21 (9): 986-988.

Vaghefi, A., and V. Sarhangian. 2009. "Contribution of Simulation to the Optimization of Inspection Plans for Multi-stage Manufacturing Systems." Computers \& Industrial Engineering 57 (4): 1226-1234.

Valenzuela, J. F., J. S. Smith, and J. L. Evans. 2004. "Allocating Solder-paste Printing Inspection in High Volume Electronics Manufacturing." IIE Transactions 36 (12): 1171-1181.

Van Volsem, S., and H. Van Landeghem. 2003. "Optimizing Inspection Strategies for Multi-stage Processes: An Exploratory Modeling Framework and Simulation." Qualité Et Sûreté De Fonctionnement 2-9.

Van Volsem, S., W. Dullaert, and H. Van Landeghem. 2007. "An Evolutionary Algorithm and Discrete Event Simulation for Optimizing Inspection Strategies for Multi-stage Processes." European Journal of Operational Research 179 (3): 621-633.

Veatch, M. H. 2000. "Inspection Strategies for Multistage Production Systems with Time-varying Quality.” International Journal of Production Research 38 (4): 837-853.

Verduzco, A., J. R. Villalobos, and B. Vega. 2001. "Information-based Inspection Allocation for Real-time Inspection Systems." Journal of Manufacturing Systems 20 (1): 13-22.

Villalobos, J. R., and J. W. Foster. 1991. "Some Results from a Model of Dynamic Inspection Allocation." Computers \& Industrial Engineering 21 (1-4): 355-358.

Villalobos, J. R., J. W. Foster, and R. L. Disney. 1993. "Flexible Inspection Systems for Serial Multi-stage Production Systems.” IIE Transactions 25 (3): 16-26.

Viswandham, N., S. M. Sharma and M. Taneja. 1996.Inspection allocation in manufacturing systems using stochastic search techniques. IEEE Transactions on Systems, Man, and Cybernetics - Part A: Systems and Humans. 26 (2) : 222-230.

Volsem, S. 2010. "Joint Optimisation of All Inspection Parameters for Multistage Processes: Evolutionary Algorithm and Simulation." International Journal of Innovative Computing and Applications 2 (3): 170-177.

White, L. S. 1966. “The Analysis of a Simple Class of Multistage Inspection Plans.” Management Science 12 (9): 685-693.

Winchell, W. 1996. Inspection and Measurement in Manufacturing: Keys to Process Planning and Improvement. Dearborn, MI: Society of Manufacturing Engineers.

Woo, W. K., and J. E. Metcalfe. 1972. "Optimal Allocation of Inspection Effort in Multi-stage Manufacturing Processes.” Western Electric Engineer 16: 3-16.

Yao, D. D., and S. Zheng. 1999a. "Sequential Inspection under Capacity Constraints." Operations Research 47 (3): $410-421$.

Yao, D. D., and S. Zheng. 1999b. "Coordinated Quality Control in a Two-stage System." IEEE Transactions on Automatic Control 44 (6): 1166-1179.

Yum, B. J., and E. D. McDowell. 1981. “The Optimal Allocation of Inspection Effort in a Class of Nonserial Production Systems.” IIE Transactions 13 (4): 285-293.

Yum, B. J., and E. D. McDowell. 1987. "Optimal Inspection Policies in a Serial Production System including Scrap Rework and Repair: An MILP Approach.” International Journal of Production Research 25 (10): 1451-1464.

Zheng, S. 2000. "Dynamic Quality Control in Assembly Systems.” IIE Transactions 32 (9): 797-806.

Zhou, M., and C. Zhao. 2002. "An Optimization Model and Multiple Matching Heuristics for Quality Planning in Manufacturing Systems." Computers \& Industrial Engineering 42 (1): 91-101. 